\title{
Continuous-Flow Fast Atom Bombardment Mass Spectrometry of Oligonucleotides
}

\author{
Richard B. van Breemen, LeRoy B. Martin, and John C. Le \\ Department of Chemistry, North Carolina State University, Raleigh, North Carolina, USA
}

\begin{abstract}
Although frit-fast atom bombardment (frit-FAB) and continuous-flow FAB mass spectrometry have become standard methods for the analysis of peptides and peptide mixtures, these techniques have not been applied previously to the analysis of oligonucleotides. Mobilephase composition, flow rate, and sample size were optimized for the analysis of oligonucleotides by negative ion frit-FAB mass spectrometry (a type of continuous-flow FAB mass spectrometry). With a mobile phase consisting of methanol/water/triethanolamine $(80: 20: 0.5, \mathrm{v} / \mathrm{v} / \mathrm{w})$, flow injection frit-FAB analysis of oligonucleotides showed lower limits of detection compared to standard probe FAB mass spectrometry. For example, in order to obtain a signal-to-noise ratio of 3:1, $38 \mathrm{pmol}$ of $\mathrm{d}$ (GTTAAC) were required for frit-FAB mass spectrometry and $62 \mathrm{pmol}$ were required for standard probe FAB mass spectrometry. The largest difference between frit-FAB and standard probe $F A B$ was observed for $d(p C)_{5}$, for which the limit of detection by frit-FAB was approximately 11-fold lower than by standard FAB mass spectrometry. Adjustment of the mobile phase to $\mathrm{pH} 7$ with trifluoroacetic acid increased the limit of detection (reduced sensitivity) a minimum of sixfold. Equimolar mixtures of two or three oligonucleotides produced deprotonated molecules in identical relative abundances whether analyzed by frit-FAB or standard probe FAB mass spectrometry. Finally, frit-FAB liquid chromatography mass spectrometry was demonstrated by separating mixtures of oligonucleotides on a $\beta$-cyclodextrin high-performance liquid chromatography column with a mobile phase containing methanol, water, and triethanolamine. (J Am Soc Mass Spectrom 1991, 2, 157-163)
\end{abstract}

S ince its introduction by Barber and co-workers [1-3], fast atom bombardment (FAB) has become a standard method for the analysis of polar, nonvolatile, high molecular weight, and thermally labile compounds [4]. In FAB, sample ions are desorbed from a liquid matrix of low volatility, such as glycerol, as a result of bombardment by energetic atoms, usually xenon, at 3-10 kV. Recently, FAB mass spectrometry has been coupled with high-performance liquid chromatography (HPLC) by Ito and co-workers [5-7] in a system called frit-FAB liquid chromatography mass spectrometry (frit-FAB LC/MS), A similar technique, continuous-flow FAB mass spectrometry, was developed by Caprioli and co-workers first for flow injection analysis [8-10] and later for LC/MS [11].

During frit-FAB and continuous-flow FAB mass spectrometry, the solvent flow, which contains a small percentage of $\mathrm{FAB}$ liquid matrix, is pumped through a capillary inside the FAB probe onto the surface of the FAB sample stage at a rate of approximately $5 \mu \mathrm{L} / \mathrm{min}$. The volatile solvents evaporate, leaving behind pri-

Address reprint requests to Richard B. van Breemen, Department of Chemistry, Box 8204, North Carolina State University, Raleigh, NC 27695. marily analyte and a thin film of FAB matrix. In frit-FAB, the sample flows through a porous stainless steel frit into the ion source of the mass spectrometer. The fast atom beam is focused on the surface of the frit, so that sample ions are desorbed as they flow through the frit into the ion source.

Advantages of continuous-flow FAB and frit-FAB mass spectrometry over the standard $\mathrm{FAB}$ probe method of sample introduction include the ability to carry out on-line HPLC separations with detection by FAB mass spectrometry [5], reduced chemical noise from the FAB matrix [8], increased signal-to-noise ratio [8], and less suppression of sample ions when mixtures of samples are analyzed $[9,10]$. Examples of classes of compounds that have been analyzed by continuous-flow or frit-FAB LC/MS include peptides [11-13], bile acids [6], and oligosaccharides [7]. In addition, a series of mononucleotides and metallated mononucleotides has been analyzed by Bertrand et al. [14] using continuous-flow FAB.

Although no applications of frit-FAB or continuous-flow FAB mass spectrometry have been reported previously for the analysis of oligonucleotides, standard FAB ionization of oligonucleotides has been studied by several investigators. Grotjahn et al. [15-17] developed procedures for the molecular 
weight determination and sequencing of small oligonucleotides up to approximately eight nucleotides in length by using negative ion $F A B$ mass spectrometry. Although limits of detection were not determined, Grotjahn et al. [17] used $10 \mathrm{nmol}$ per analysis to obtain sequence data. Also, FAB ionization coupled with tandem mass spectrometry has been applied to the sequence determination of oligonucleotides up to six nucleotides in length by Panico et al. [18] and Cerny et al. [19]. Because of the relatively large sample quantities required for these analyses, refinements in the procedures are needed to improve their limits of detection. The purpose of the present study was to apply frit-FAB to the analysis of oligonucleotides in order to improve the signal-to-noise ratio, reduce chemical noise, and therefore improve the limit of detection of FAB mass spectrometry for oligonucleotide samples. Another objective was to demonstrate the on-line HPLC separation of oligonucleotides followed by FAB mass spectrometric analysis (LC/MS).

\section{Experimental}

HPLC methanol was purchased from Fisher Scientific (Fair Lawn, NJ), and high purity water was prepared by using a Millipore (Bedford, MA) Milli-Q Water System. Triethanolamine and glycerol were purchased from Aldrich Chemical Co. (Milwaukee, WI), and oligonucleotides were purchased from Sigma Chemical Co. (St. Louis, MO). Stock solutions of the synthetic oligonucleotides were prepared, and their concentrations were standardized by measuring oligonucleotide absorbances at $260 \mathrm{~nm}$. Extinction coefficients for the oligonucleotides were calculated according to the nearest-neighbor method of Cantor and co-workers [20, 21] as modified by Edwards et al. [22]. Oligonucleotide solutions of decreasing concentration were prepared by serial dilution by using the HPLC mobile phase, which consisted of methanol/water/triethanolamine $(80: 20: 0.5, v / v / w)$. For some experiments, the $\mathrm{pH}$ of the mobile phase was adjusted to 7.0 with trifluoroacetic acid. Alf $\mathrm{pH}$ measurements were uncorrected for a solution containing $80 \%$ methanol. However, the $\mathrm{pH}$ correction factor for a methanol/water $(70: 30, \mathrm{v} / \mathrm{v})$ solution has been reported to be $-0.17 \mathrm{pH}$ units [23].

For flow injection analyses, an Applied Biosystems (Foster City, CA) Model 140A Dual Syringe Solvent Delivery System, equipped with a Rheodyne (Cotati, CA) Model 8125 injector, was connected without a chromatographic column to a JEOL (Tokyo, Japan) frit-FAB interface by using a $60 \mu \mathrm{m}$ (i.d.) $\times 50 \mathrm{~cm}$ fused silica capillary. For one set of experiments, siloxyl groups on the inner surface of the fused silica tubing were deactivated by treatment with Glas-Treet (Regis Chemicals, Morton Grover IL), which contains an alkylchlorosilane reagent. The HPLC pump was operated at a flow rate of $5 \mu \mathrm{L} / \mathrm{min}$. For each series of analyses, $1 \mu \mathrm{L}$ of a standard solution was injected into the HPLC mobile phase, beginning with the least concentrated sample. Blank injections were made between analyses to verify that there was no carryover of sample from the previous injection. Because no splitting of the sample flow was carried out, the entire sample was transferred to the frit-FAB ion source of the mass spectrometer. The frit-FAB ion source temperature was $46^{\circ} \mathrm{C}$.

Separations of oligonucleotide mixtures were carried out by using an Astec (Whippany, NJ) Cyclobond I ( $\beta$-cyclodextrin) HPLC column $(4.6 \mathrm{~mm} \times 25 \mathrm{~cm})$ operating at a flow rate of $200 \mu \mathrm{L} / \mathrm{min}$. The capillary of the frit-FAB interface was connected to the HPLC column through a splitter, so that the eluate flowing to the mass spectrometer could be adjusted to approximately $5 \mu \mathrm{L} / \mathrm{min}$. Mixtures of oligonucleotides, consisting of either $d(p T)_{2}$ and $d(p A)_{2}, d(p T)_{2}$ and $d(p C)_{3}$, or $\mathrm{d}(\mathrm{pA})_{2}$ and $\mathrm{d}(\mathrm{pT})_{4}$, were prepared by using the mobile phase so that the final concentration of each oligonucleotide was approximately $2 \mathrm{mM}$. For each LC/MS analysis, $15 \mu \mathrm{L}$ of each mixture (approximately $30 \mathrm{nmol}$ of each oligonucleotide) was injected onto the HPLC column. Separations were carried out either with isocratic methanol/water/triethanolamine $(50: 50: 0.5, v / v / w)$ or with a linear gradient over 15 $\mathrm{m}$ in of $80: 20: 0.5$ to $15: 85: 0.5(\mathrm{v} / \mathrm{v} / \mathrm{w})$ methanol/water/triethanolamine.

Negative ion FAB mass spectra were obtained by using a JEOL (Tokyo, Japan) JMS-HX110HF doublefocusing mass spectrometer that was equipped with a JMA-DA5000 data system. During the acquisition of each mass spectrum during standard $F A B$ and flow injection frit-FAB analysis, approximately 10 scans were averaged by the data system. The time requircd for these scans (approximately 45 s) corresponded to the width of the sample peak as it was desorbed from the frit- $F A B$ probe. For limit of detection measurements, a range of $120 \mathrm{u}$ was scanned over approximately $5 \mathrm{~s}$. During frit-FAB LC/MS analysis of oligonucleotide mixtures, $1000 \mathrm{u}$ were scanned over approximately $5 \mathrm{~s}$. Mass spectra were calibrated by using static FAB with sodium iodide in glycerol as the reference sample. Xenon fast atoms at $6 \mathrm{kV}$ were used for ionization. The accelerating voltage was $10 \mathrm{keV}$, and the dynamic resolution was adjusted to between 1000 and 1800 for all analyses.

\section{Results and Discussion}

Because Grotjahn et al. [15-17] used glycerol as the FAB matrix for the analysis of oligonucleotides and because glycerol solutions in aqueous methanol [12, 24] or acetonitrile [10, 11] have functioned satisfactorily as mobile phases for most other continuous-flow FAB applications, a mobile phase consisting of methanol, water, and glycerol was initially evaluated for the analysis of oligonucleotides by frit-FAB mass spectrometry. The ratio of methanol, water, and glyc- 
Table 1. Limits of detection of frit-FAB mass spectrometry and standard probe FAB mass spectrometry for $[\mathrm{M}-\mathrm{H}]^{-}$ions of oligonucleotides with triethanolamine as the FAB matrix

\begin{tabular}{|c|c|c|c|}
\hline \multirow[b]{2}{*}{ Oligonucleotide } & \multicolumn{2}{|c|}{$\begin{array}{l}\text { Frit-FAB mass spectrometry } \\
\left(\text { (pmol } \pm \text { s.d. }{ }^{a}\right)\end{array}$} & \multirow{2}{*}{$\begin{array}{l}\text { Standard FAB mass spectrometry } \\
\qquad(\mathrm{pmol} \pm \text { s.d. })\end{array}$} \\
\hline & $\mathrm{pH} 10$ & $\mathrm{pH} 7^{\mathrm{b}}$ & \\
\hline $\begin{array}{l}d(p C)_{5} \\
d(p T)_{6} \\
d(p A)_{5} \\
d(G T T A A C)\end{array}$ & $\begin{array}{l}3.5 \pm 0.3 \\
38 \pm 2 \\
43 \pm 4 \\
38 \pm 7\end{array}$ & $\begin{array}{l}>350 \\
238 \pm 14 \\
345 \pm 7 \\
>400\end{array}$ & $\begin{array}{l}38 \pm 5 \\
53 \pm 2 \\
55 \pm 6 \\
62 \pm 9\end{array}$ \\
\hline
\end{tabular}

$a_{n} \geq 3$.

${ }^{\mathrm{h}}$ Addition of trifluoroocetic acid wos used to obtain $\mathrm{pH} 7$,

erol was adjusted until a stable signal could be obtained for $d(p A)_{6}$. Stability for frit-FAB mass spectrometry is defined here as the continuous and reproducible production of ions from the surface of the frit without freezing of the mobile phase or excessive sputtering caused by mobile-phase vaporization behind the frit.

With methanol/water/glycerol (80:20:0.5, v/v/w) as the mobile phase, abundant deprotonated molecules $\left[\mathrm{M}-\mathrm{H}^{-}\right.$of the purine homopolymer, $\mathrm{d}(\mathrm{pA})_{6}$, were detected by using negative ion frit-FAB mass spectrometry. However, virtually no deprotonated molecules of the pyrimidine homopolymer, $\mathrm{d}(\mathrm{pC})_{5}$, could be detected under the same instrumental conditions. Because pyrimidine bases have a higher proton affinity than purine bases, $\mathrm{d}(\mathrm{pC})_{5}$ probably did not form abundant deprotonated molecules in glycerol. The purine homopolymer, $\mathrm{d}(\mathrm{pA})_{6}$, was easily deprotonated in glycerol and therefore formed more abundant deprotonated molecules that were detected by FAB mass spectrometry. To enhance the formation of deprotonated molecules of oligonucleotides containing purine bases, a more basic FAB matrix was required.

A stronger base than glycerol, triethanolamine [25] has been shown to be an effective FAB matrix for the mass spectrometric analysis of oligonucleotides [19, 26]. For all subsequent measurements using frit-FAB mass spectrometry, the mobile phase contained methanol and water as before, but triethanolamine was used instead of glycerol. Frit-FAB mass spectrometry using this new mobile phase produced deprotonated molecules for all oligonucleotides investigated, including homopolymers of purine nucleotides, pyrimidine nucleotides, and oligonucleotides containing a mixture of purine and pyrimidine bases.

The limits of detection for $\mathrm{d}(\mathrm{pC})_{5}, \mathrm{~d}(\mathrm{pT})_{6}, \mathrm{~d}(\mathrm{pA})_{6}$, and $d(G T T A A C)$ were determined by using frit-FAB mass spectrometry with a mobile phase containing triethanolamine as described above. For comparison, the detection limits for the same compounds were determined by using the standard $\mathrm{FAB}$ probe with triethanolamine as the matrix. The results of both series of measurements are shown in Table 1. In these studies, the limit of detection was defined as a signalto-noise ratio of 3:1.
Mass spectra illustrating the determination of the limits of detection for $\mathrm{d}(\mathrm{pC})_{5}$ and $\mathrm{d}(\mathrm{pT})_{6}$ are shown in Figures 1 and 2, respectively. The greatest difference between frit-FAB and standard probe $\mathrm{FAB}$ was observed for $d(p C)_{5}$, for which the limit of detection using frit-FAB LC/MS was approximately 11-fold lower (Table 1 and Figure 1). In other cases, the limit of detection of frit-FAB was less than two-fold lower than standard $F A B$ mass spectrometry.

One (1) $\mu \mathrm{I}$, volumes of standard solutions were analyzed by flow injection using frit-FAB because they represented a small volume that could be reproducibly measured and injected with the equipment used in this investigation. At a flow rate of $5 \mu \mathrm{L} / \mathrm{min}$, the minimum band width would have been $12 \mathrm{~s}$. However, the bands were typically $45 \mathrm{~s}$ wide (as shown in Figure 3a) for a $1-\mu \mathrm{L}$ injection containing 60 pmol of $\mathrm{d}(\mathrm{pT})_{4}$. Band broadening might be the result of dead volume in the HPLC system, sample adsorption to hydroxyl groups on the inside of the fused

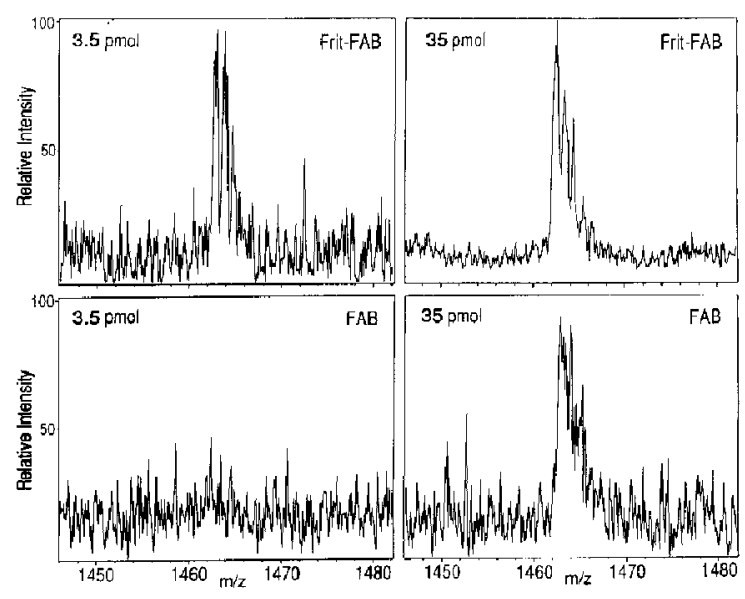

Figure 1. Comparison of the limits of detection for the deprotonated molecule, $[\mathrm{M}-\mathrm{H}]^{-}$, of $\mathrm{d}(\mathrm{pC})_{5}$ by using negative ion frit-FAB mass spectrometry and standard probe negative ion FAB mass spectrometry. The frit-FAB mobile phase consisted of methanol/water/triethanolamine $(80: 20: 0.5, v / v / w)$. Triethanolamine was used as the matrix for the standard probe $\mathrm{FAB}$ mass spectra. 

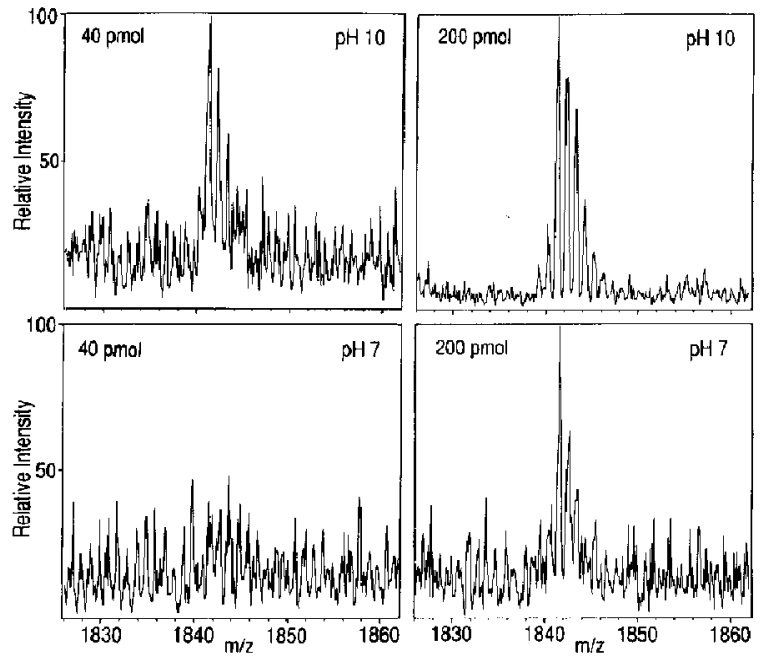

Figure 2. The limits of detection of frit-FAB mass spectrometry for the measurement of $[\mathrm{M}-\mathrm{H}]^{-}$ions from $\mathrm{d}(\mathrm{pT})_{6}$ determined by using a mobile phase consisting of methanol/water/triethanolamine $(80: 20: 0.5, \mathrm{v} / \mathrm{v} / \mathrm{w})$ at $\mathrm{pH} 10$ or, following addition of trifluoroacetic acid, $\mathrm{pH} 7$.

silica capillary, effects of the frit on the frit- $F \Lambda B$ probe, or a combination of these factors.

One possible explanation for broad band widths during flow injection frit-FAB analysis of oligonucleotides might be hydrogen bonding of the sample molecules to siloxyl groups on the inner surface of the fused silica capillary tubing. In order to minimize these interactions, the capillary was deactivated by treatment with a silanizing reagent, and the band width of a 1- $\mu \mathrm{L}$ injection containing $60 \mathrm{pmol}$ of $\mathrm{d}(\mathrm{pT})_{4}$ was again determined. Instead of decreasing the band width, silanization of the capillary had the opposite effect (Figure 3b). Apparently, hydrophobic interactions occurred between the oligonucleotide in the mobile phase and the alkylsilyl groups on the capillary wall. Therefore, hydrogen bonding of the analyte to the fused silica capillary was not the primary cause of band broadening during frit-FAB.

Next, band broadening on the frit-FAB probe was investigated as a function of the matrix concentration in the mobile phase. Because methanol and water probably evaporated immediately from the frit surface, the less volatile triethanolamine would have been the principal solvent responsible for carrying any excess oligonucleotides away from the center of the frit, which was the point at which the fast atom beam was focused. At the fringes of the frit, the remaining matrix would have evaporated, leaving behind any excess sample. The rate of solvent flowing radially from the frit center would determine the residence time of samples exposed to the FAB beam. Because only $0.5 \%$ of the mobile phase was triethanolamine, the flow of solvent to the perimeter of the frit was relatively low compared to the $5-\mu \mathrm{L} \min$

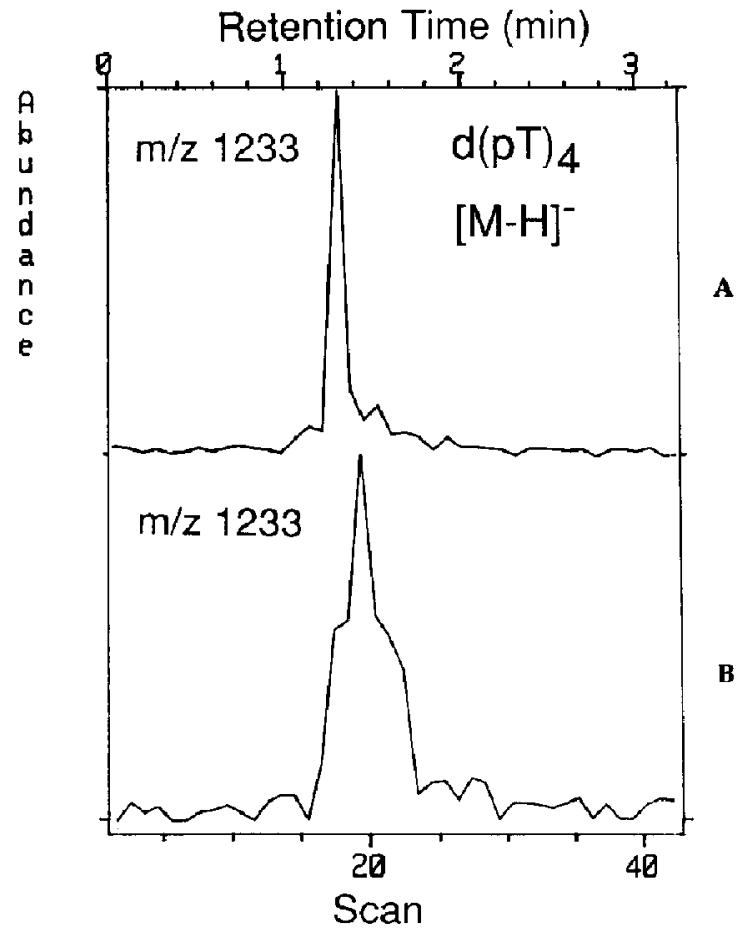

Figure 3. Comparison of the band profiles of the $[\mathrm{M}-\mathrm{H}]^{-}$ion at $m / z 1233$ of $d(p T)_{4}$ obtained by flow injection frit-FAB mass spectrometry of $1-\mu \mathrm{L}$ solutions onto either (a) untreated fused silica capillary or (b) fused silica capillary that had been silanized to deactivate hydroxyl groups.

flow rate of the entire mobile phase. Therefore, increasing the concentration of matrix in the mobile phase might decrease the band width.

Alternatively, if the concentration of triethanolamine in the mobile phase were increased, band broadening might increase at the frit because the surface area of analyte plus matrix exposed to the FAB beam would be increased. Assuming that analyte desorption occurs only in the region with significant matrix, ions would be desorbed for a longer period of time before either the sample or the matrix at the surface of the frit became exhausted.

In order to determine how the percentage of matrix in the mobile phase affected the sample band width during frit-FAB mass spectrometry, band widths for $1-\mu \mathrm{L}$ injections of $23 \mathrm{pmol} \mathrm{d}(\mathrm{pC})_{5}$ were measured by using a mobile phase consisting of methanol/water (80:20) containing either $0.5 \%, 1.0 \%$, or $2.0 \%$ triethanolamine. Instead of becoming narrower as the percent composition of matrix in the mobile phase increased, the band width of $\mathrm{d}(\mathrm{pC})_{5}$ increased slightly, and the relative abundance of the deprotonated molecule decreased (data not shown).

Because the $\mathrm{pH}$ of the methanol/water/triethanolamine mobile phase was approximately 10 , dissolution of the fused silica capillary tubing might 
be expected to occur. Therefore, the stability of the tubing and performance of the frit-FAB LC/MS interface was evaluated over a period of two months. No damage to the frit or capillary and no loss of performance of the system were observed as a result of the high $\mathrm{pH}$ of mobile phase. However, it was necessary to store the mobile phase in polypropylene bottles, because sodium and potassium adducts of oligonucleotides were observed in the frit-FAB mass spectra following storage of the solvent in glass flasks.

To extend the life of HPLC columns packed with silica-based stationary phases, the $\mathrm{pH}$ of the mobile phase should be less than 8 . Although a mobile phase for frit-FAB containing glycerol would have met these $\mathrm{pH}$ requirements, this matrix was shown to be inferior to triethanolamine for the frit-FAB mass spectrometric analysis of oligonucleotides containing pyrimidine bases. If triethanolamine had matrix properties superior to glycerol other than its greater proton affinity, then a mobile phase containing triethanolamine adjusted to $\mathrm{pH} 7 \mathrm{might}$ also be superior to glycerol. Furthermore, a volatile acid used to adjust the $\mathrm{pH}$ of the mobile phase might rapidly evaporate from the frit surface along with methanol and water, leaving behind a more alkaline triethanolamine solution to promote the formation of deprotonated sample molecules.

In order to test these hypotheses, the limits of detection of $d(\mathrm{pC})_{5}, d(\mathrm{pT})_{6}, d(\mathrm{pA})_{6}$, and $d$ (GTTAAC) were determined by direct injection frit- $F A B$ with a mobile phase containing methanol, water, and triethanolamine that had been adjusted to $\mathrm{pH} 7$ by trifluoroacetic acid. The results are summarized in Table 1, and exemplary mass spectra comparing the limits of detection of $\mathrm{d}(\mathrm{pT})_{6}$ at $\mathrm{pII} 10$ and $\mathrm{pH} 7$ are shown in Figure 2. Not only was the $\mathrm{pH} 7$ mobile phase less effective than the unmodified $\mathrm{pH} 10$ solution, it was also inferior to standard $\mathrm{FAB}$ mass spectrometry. No ions could be detected for d(GTTAAC) or $\mathrm{d}(\mathrm{pC})_{5}$ for the quantities tested. The $\mathrm{pH}$ at the surface of the frit probably remained near 7 instead of approaching $\mathrm{pH} \mathrm{10}$, and triethanolamine at $\mathrm{pH} 7$ was an inferior matrix compared to unbuffered glycerol. The $\mathrm{pH}$ of the mobile phase appears to be critical for the formation of deprotonated oligonucleotides during frit-FAB mass spectrometry.

During the analysis of peptide mixtures by positive ion $\mathrm{FAB}$ mass spectrometry, hydrophobic peptides have been shown to form more abundant protonated molecules relative to those from hydrophilic peptides in the mixture $[9,10]$. Caprioli and co-workers $[9,10]$ reported that continuous-flow FAB mass spectrometry reduced the ion suppression effects observed for mixtures of peptides during standard FAB mass spectrometry. In order to determine whether any ion suppression effects for oligonucleotide mixtures could be minimized by using frit-FAB mass spectrometry, equimolar solutions of $\mathrm{d}(\mathrm{pC})_{5}, \mathrm{~d}(\mathrm{pA})_{6}$, and $\mathrm{d}(\mathrm{GT}$ TAAC) were prepared and analyzed by negative ion
frit-FAB LC/MS and standard FAB mass spectrometry. The frit-FAB mobile phase consisted of methanol/water/triethanolamine $(80: 20: 0.5, \mathrm{v} / \mathrm{v} / \mathrm{w})$, and triethanolamine was used as the matrix for standard probe FAB. The relative abundances of the $[\mathrm{M}-$ $\mathrm{H}^{-}$ions for all three oligonucleotides in the mixture were identical, whether they were analyzed by frit$F A B$ or standard $F A B$ mass spectrometry (data not shown). This indicated that there was no difference in ion suppression between frit-FAB and standard FAB mass spectrometry for the mixture studied.

Initial attempts at reversed-phase chromatographic separations of oligonucleotide mixtures on a polymeric phenyl column were unsuccessful. Therefore, frit-FAB LC/MS analyses of oligonucleotide mixtures were carried out by using normal phase interactions of analytes with the polar hydroxyl groups on a $\beta$ cyclodextrin HPLC column (Figure 4). During LC/MS analysis of a mixture of $\mathrm{d}(\mathrm{pT})_{2}$ and $\mathrm{d}(\mathrm{pA})_{2}, \mathrm{~d}(\mathrm{pT})_{2}$ eluted furst from the cyclodextrin column. In other separations, $d(\mathrm{pT})_{4}$ eluted prior to $d(\mathrm{pA})_{2}$, and $d(\mathrm{pT})_{2}$ eluted before $\mathrm{d}(\mathrm{pC})_{3}$.

The reconstructed total ion chromatogram and selected mass chromatograms showing the $\left[\mathrm{M}-\mathrm{H}^{-}\right.$ ions of the oligonucleotides $\mathrm{d}(\mathrm{pT})_{2}$ and $\mathrm{d}(\mathrm{pA})_{2}$ during LC/MS analysis are shown in Figure 4. The continuous production of abundant matrix ions obscured sample ions in the reconstructed total ion chromatogram. However, the mass chromatograms of the $[\mathrm{M}-\mathrm{H}]^{-}$ions of the two oligonucleotides confirmed that they were completely resolved by chromatography (Figure 4). Following background subtraction, the mass spectra of $\mathrm{d}(\mathrm{pT})_{2}$ and $\mathrm{d}(\mathrm{pA})_{2}$ from the LC/MS chromatogram discussed above are shown in Figure $5 \mathrm{a}$ and $\mathrm{b}$, respectively. Abundant deprotonaled molecules, $[\mathrm{M}-\mathrm{H}]^{-}$, were detected for both oligonucleotides with virtually no fragmentation.

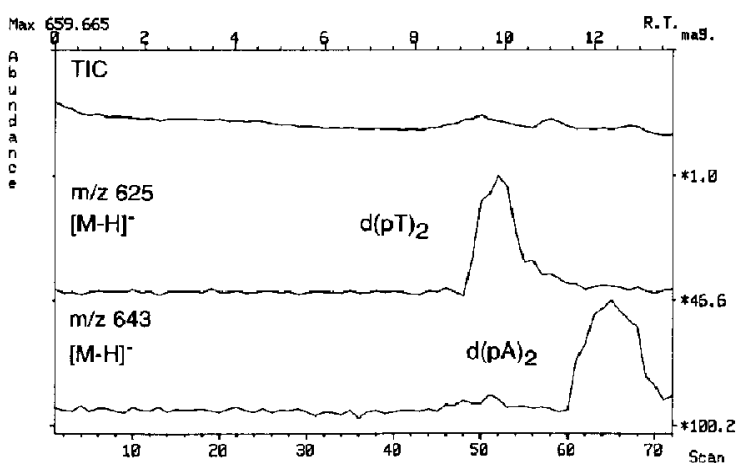

Figure 4. Total ion chromatogram (TIC) and mass chromatograms showing the $[\mathrm{M}-\mathrm{H}]^{-}$ions of $d(\mathrm{pT})_{2}$ and $\mathrm{d}(\mathrm{pA})_{2}$ obtained during frit-FAB LC/MS analysis. A mixture containing $30 \mathrm{nmol}$ of each oligonucleotide was injected onto the HPLC column, which was operated at a flow rate of $200 \mu \mathrm{L} / \mathrm{min}$. The flow was split so that only $5 \mu \mathrm{L} / \mathrm{min}$ (750 pmol of each oligonucleotide) entered the mass spectrometer. 


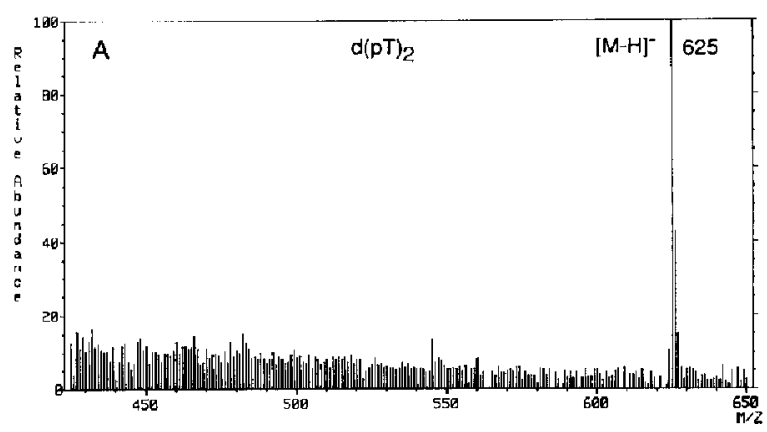

$\mathbf{A}$

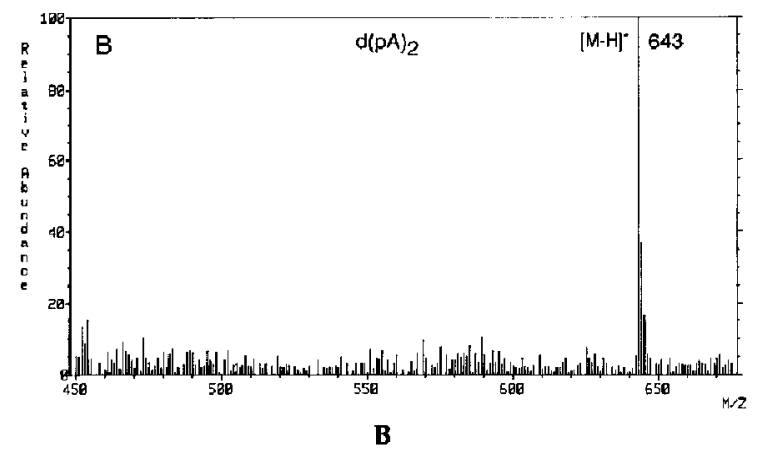

Figure 5. Frit-FAB mass spectra of approximately $750 \mathrm{pmol}$ each of (a) $d(p T)_{2}$ and (b) $d(p A)_{2}$ obtained during the LC/MS analysis shown in Figure 4 . These mass spectra have been background-subtracted to eliminate triethanolamine matrix ions, which were abundant below approximately $m / z 500$.

\section{Conclusions}

This investigation represents the first successful application of frit-FAB mass spectrometry or any type of continuous-flow FAB mass spectrometry to the analysis of oligonucleotides. Compared to standard probe $F A B$, frit-FAB improved the limit of detection from 1.3- to 11-fold for the oligonucleotides investigated. The high $\mathrm{pH}$ of the triethanolamine aqueous solution was found to be essential for the low detection limits of frit-FAB for the analysis of oligonucleotides. During flow injection frit-FAB analysis of oligonucleotides, band broadening was observed and probably was the result of dead volume in the plumbing system. Adsorption of oligonucleotides to hydroxyl groups on the fused silica capillary and excessive sample residence time at the frit center were shown to be insignificant causes of band broadening.

In addition to flow injection analysis of oligonuclentides by frit-FAB, LC/MS was demonstrated by using a cyclodextrin column to separate a mixture of oligonucleotides. Although a mobile phase at $\mathrm{pH} 10$ will limit the use of some HPLC columns containing silica-based stationary phases for oligonucleotide separations, a silica column containing immobilized cyclodextrin was stable during the separations reported here. The use of a cyclodextrin column avoids ion exchange chromatography that requires high ionic strength buffers to elute oligonucleotides. Also overcome by this approach is the need for postcolumn addition of matrix [27], which could circumvent the problem of high $\mathrm{pH}$ in the mobile phase during chromatography. Although only simple oligonucleotide mixtures have been investigated by LC/MS so far, the separation power of HPLC combined with the speed and convenience of on-line mass selective detection should make this LC/MS techrique of great utility in the characterization of oligonucleotide mixtures.

\section{Acknowledgments}

Preliminary results of this investigation were presented at the 38th ASMS Conference on Mass Spectrometry and Allied Topics, Tucson, Arizona, 1990. Mass spectra were obtained at the Mass Spectrometry Laboratory for Biotechnology Research at North Carolina State University, supported in part by the North Carolina Biotechnology Center. The authors wish to thank Professor D. W. Armstrong of the University of Missouri for his suggestions regarding the chromatographic separation of oligonucleotides.

\section{References}

1. Barber, M.; Bordoli, R. S.; Sedgwick, R. D.; Tyler, A. N. J. Chem. Soc., Chem. Commun. 1981, 325-327.

2. Barber, M.; Bordoli, R. S.; Garner, G. V.; Gordon, D. B.; Sedgwick, R. D.; Tetler, L. W.; Tyler, A. N. Biochem. J. 1981, 197, 401-404.

3. Barber, M.; Bordoli, R. S.; Elliot, G. J.; Sedgwick, R. D.; Tyler, A. N. Anal. Chem. 1982, 54, 645A-657A.

4. Fenselau, C.; Cotter, R. J. Chem. Rev. 1987, 87, 501-512.

5. Ito, Y.; Takeuchi, T.; Ishii, D.; Goto, M. J. Chromatogr. 1985, 346, 161-166.

6. Ito, Y.; 'Takeuchi, T.; Ishii, D.; Goto, M.; Mizuno, T. I. Chromatogr. 1986, 358, 201.

7. Ito, Y.; Takeuchi, T.; Ishii, D.; Goto, M.; Mizuno, T. J. Chromatogr. 1987, 391, 296.

8. Caprioli, R. M.; Fan, T.; Cottrell, J. S. Anal. Chem. 1986, 58, 2949-2954.

9. Caprioli, R. M.; Moore, W. T.; Fan, T. Rapid Commun. Mass Spectrom. 1987, 1, 15-18.

10. Caprioli, R. M.; Moore, W. T.; Petrie, G.; Wilson, K. Int. J. Mass Spectrom. Ion Processes 1988, 86, 187-199.

11. Caprioli, R. M.; Moore, W. T.; Dague, B.; Martin, M. J. Chromatogr. 1988, 443, 355-362.

12. Games, D. E.; Pleasance, S.; Ramsey, E. D.; McDowall, M. A. Biomed. Environ. Mass Spectrom. 1988, 15, 179-182.

13. Ashcroft, A. E.; Chapman, J. R.; Cottrell, J. S. J. Chromatogr. 1987, 394, 15.

14. Bertrand, M. J.; Benham, V.; St-Louis, R.; Evans, M. J. Can. J. Chem., 1989, 67, 910-920.

15. Grotjahn, L.; Frank, R.; Blocker, H. Nucleic Acids Res. 1982, 10, 4671-4678.

16. Grotjahn, L.; Frank, R.; Blocker, H. Int. I. Mass Spectrom. Ion Processes 1983, 46, 439-442.

17. Grotjahn, L.; Frank, R.; Blocker, H. Biomed. Mass Spectrom. 1985, 12, 514-524.

18. Panico, M.; Sindona, G.; Uccella, N. J. Am. Chem. Soc. 1983, 105, 5607-5610.

19. Cerny, R. L.; Tomer, K. B.; Gross, M. L.; Grotjahn, L. Anal. Biochem. 1987, 165, 175-182.

20. Cantor, C. R.; Warshaw, M. M.; Shapiro, H. Biopolymers 1970, 9, 1059-1077.

21. Cantor, C. R.; Tinoco, I. Jr. J. Mol. Biol. 1965, 13, 65-77. 
22. Edwards, E. L.; Patrick, M. H.; Ratliff, R. L.; Gray, D. M. Biochemistry 1990, 29, 828-836.

23. Ong, K. C.; Robinson, R. A.; Bates, R. C. Anal. Chem. 1964, $36,1971-1972$.

24. Lisek, C. A.; Bailey, J. E.; Benson, L. M.; Yaksh, T. L.; Jardine, I. Rap. Commun. Mass Spectrom. 1989, 3, 43-46.
25. Cook, K. D.; Todd, P. J.; Friar, D. H. Biomed. Environ. Mass Spectrom. 1989, 18, 492-497.

26. Iden, C. R.; Ricger. R. A. Biomed. Environ. Mass Spectrom. 1989, 18, 617-619.

27. Games, D. E.; Pleasance, S.; Ramsey, E. D.; McDowall, M. A. Biomed. Environ. Mass Spectrom. 1988, 15, 179-182. 